\title{
Use of focus assessed transthoracic echocardiography (FATE) in the veterinary emergency room
}

\author{
Stephany Buba Lucina ${ }^{1}$ Ana Paula Sarraff-Lopes ${ }^{2}$ Marlos Gonçalves Sousa ${ }^{3 *}$ \\ 'Departamento de Medicina Veterinária, Universidade Federal do Paraná (UFPR), Curitiba, PR, Brasil. \\ 2Escola de Ciências da Vida, Pontifícia Universidade Católica do Paraná (PUCPR), Curitiba, PR, Brasil. \\ ${ }^{3}$ Departamento de Medicina Veterinária, Universidade Federal do Paraná (UFPR), 80050-540, Curitiba, PR, Brasil. E-mail: marlos98@ufpr.br. \\ "Corresponding author.
}

ABSTRACT: The use of bedside focus assessed transthoracic echocardiography (FATE) is widespread in human medicine, and the potential for veterinary medicine has only recently been investigated. Focused echocardiographic examination can be beneficial in critically ill patients compared to other bedside diagnostic methods, as well as facilitating rapid therapeutic approaches in the emergency room. The aim of this review is to discuss FATE and identify its main applications in veterinary medicine. In this context, FATE has proved to be benefical even when carried out by a non-cardiologist physician or veterinarian. However, a few references on this subject exist in the veterinary literature and there is still a need for standardization of this technique for use in animals.

Key words: bedside, cardiology, cats, critical care, dogs.

Aplicabilidade da avaliação ecocardiográfica transtorácica focada (FATE) na sala de emergência veterinária

RESUMO: A avaliação ecocardiográfica transtorácica focada (FATE) utilizada em pacientes à beira leito já é bastante difundida na medicina, e apenas, recentemente tem se discutido a respeito deste assunto na medicina veterinária. Este exame pode trazer diversos beneficios aos pacientes críticos comparado aos outros métodos diagnósticos, além de facilitar e agilizar condutas terapêuticas na sala de emergência. O objetivo desta revisão é abordar a respeito desta modalidade de exame e identificar quais são suas principais aplicabilidades na medicina veterinária. Dentro deste contexto, a FATE tem se mostrado benéfica inclusive quando realizada por médicos ou veterinários não cardiologistas. No entanto, poucas são as referêcias veteriárias a respeito deste assunto e ainda há necessidade de uma padronização desta técnica para uso em animais.

Palavras-chave: beira leito, cão, cardiologia, gato, intensivismo.

\section{INTRODUCTION}

With recent advances in ultrasonography techniques the utility of echocardiography at the bedside in critically ill patients in the emergency room has been increased. Focus assessed transthoracic echocardiography (FATE), in these conditions, can be used to provide earlier and more accurate diagnosis, as well as to direct therapeutic choices by the medical staff (MOORE \& COPEL, 2011). From this context, the American Society of Echocardiography (ASE) in conjunction with the American College of Emergency Physicians (ACEP) has developed a consensus for the use of echocardiography in the emergency rooms in man. The consensus was named as echocardiographic examination performed at bedside - focused echocardiography (LABOVITZ et al., 2010). In veterinary medicine there is no standardization of FATE application in critically ill patients in the emergency room.

Cageside echocardiographic evaluation gives the veterinarian detailed information about the disease and direct diagnose and treatment of the emergency patient (TSE et al., 2013). FATE can be considered as an extension of the physical examination, and the term "visual stethoscope" has been coined. However, the obtained information should be interpreted in the context of each patient (MOORE \& COPEL, 2011). According to the ASE, in well-trained hands, focused echocardiography can be regarded as an accurate method, with reliable findings in the evaluation of cardiac structure and function (SPENCER et al., 2013). 
FATE is indicated for animals that have been admitted to emergency care with thoracic trauma, dyspnea, hypotension or shock. It is particularly useful in cats with dyspnea when there is suspicion of heart failure, since physical examination and thoracic radiography may not provide a definitive diagnosis in these cases. This technique allows the identification of left atrial enlargement, pleural and pericardial effusions, left ventricular systolic dysfunction and morphological changes of the mitral valve (DEFRANCESCO, 2013).

The aim of this review was to address the differences between comprehensive echocardiography (CE) and FATE, describing how to perform the focused technique, exploring the possible findings of these examinations, and thus, identifying its main applications in veterinary medicine.

\section{Comprehensive echocardiography versus FATE}

For approximately 30 years transthoracic echocardiography has been considered the primary method for diagnosis and management of dogs and cats with cardiovascular disease (CHETBOUL, 2010). It is a non-invasive examination used to evaluate the anatomy and function of the heart and adjacent structures. Three echocardiographic modalities are used routinely in veterinary cardiology, $\mathrm{M}$ mode, two-dimensional echocardiography and Doppler, and each of these methods has its own application (WARE, 2011).

Despite the central role of transthoracic echocardiography in veterinary cardiology the echocardiographer must be aware of its limitations. Patient preparation (clipping and application of gel), a suitable table, as well as correct positioning of the animal, are important factors in producing the high quality images necessary for a reliable examination. Examination quality is also dependent on the correct positioning of the probe on the patient's chest and machine set-up. Ultrasonographic examination is highly dependent on the acquisition and interpretation of images by the echocardiographer, and findings should always be correlated with the history and physical examination of the patient in order to obtain a definitive diagnosis (OYAMA, 2004; CÔTÉ, 2005).

Echocardiographers require prolonged training to produce reliable echocardiographic examinations but are rarely part of the staff in an emergency setting. In addition, the intensive care environment is not condusive to CE. Environmental factors, such as inappropriate lighting, and the fragile nature of the patients; i.e, respiratory distress, hemodynamic instability, make examination challenging, and patients can be compromised by being translocated for examination (CASAROTO et al., 2015). Thus, some adjustments were made to produce a standardized cardiac examination in the emergency room and a consensus has been reached for focused echocardiography in human medicine (LABOVITZ et al., 2010; MOK, 2016). In the emergency room setting echocardiography is not a comprehensive examination, rather it only includes two-dimensional and $\mathrm{M}$ mode echocardiography. Examination is abbreviated to get rapid information at the bedside in order to guide therapy and assist in patient monitoring (TSE et al., 2013).

FATE includes assessment of the relative size of the heart chambers, global cardiac function, volume status, and examination for the presence of pericardial effusion. Also, it can be used as a guide to invasive emergency room procedures such as pericardiocentesis. Diseases, such as heart tumors, thrombus, valvular dysfunction, abnormalities of heart wall motion, endocarditis and aortic dissection, can be diagnosed during FATE. However, it cannot replace $\mathrm{CE}$ as some parameters can only be examined during a complete echocardiography examination. In addition, whenever there is disagreement between the patient's clinical signs and the information obtained by FATE, a CE should be performed (LABOVITZ et al., 2010).

FATE has some advantages over other techniques for cardiovascular evaluation, it is safe, noninvasive, accessible, does not expose the patient and the staff to ionizing radiation and does not require administration of contrast. It is usually performed with portable equipment, does not require patient displacement and the result are available immediately, which allows serial assessments (MEYER et al., 2008; SPENCER et al., 2013; CASAROTO et al., 2015). FATE can be performed in sternal recumbency, standing or lateral decubitus position while the patient receives oxygen and medications (Figure 1), providing great benefits to veterinary patients (DEFRANCESCO, 2013). The time taken to complete such technique is around six minutes, which is significantly faster than CE (BEAULIEU, 2007; CASAROTO et al., 2015).

The main error in interpretation of FATE is the failure to document left ventricular dysfunction. In general, emergency physicians tend to overestimate left ventricular function. In addition, non-cardiologists are unlikely to recognize other causes of hemodynamic compromise, such as cor pulmonale or valvular abnormalities (MELAMED et al., 2009; CASAROTO et al., 2015).

\section{FATE findings and execution}

In medicine, FATE requires conventional echocardiographic views. The apical four and five 


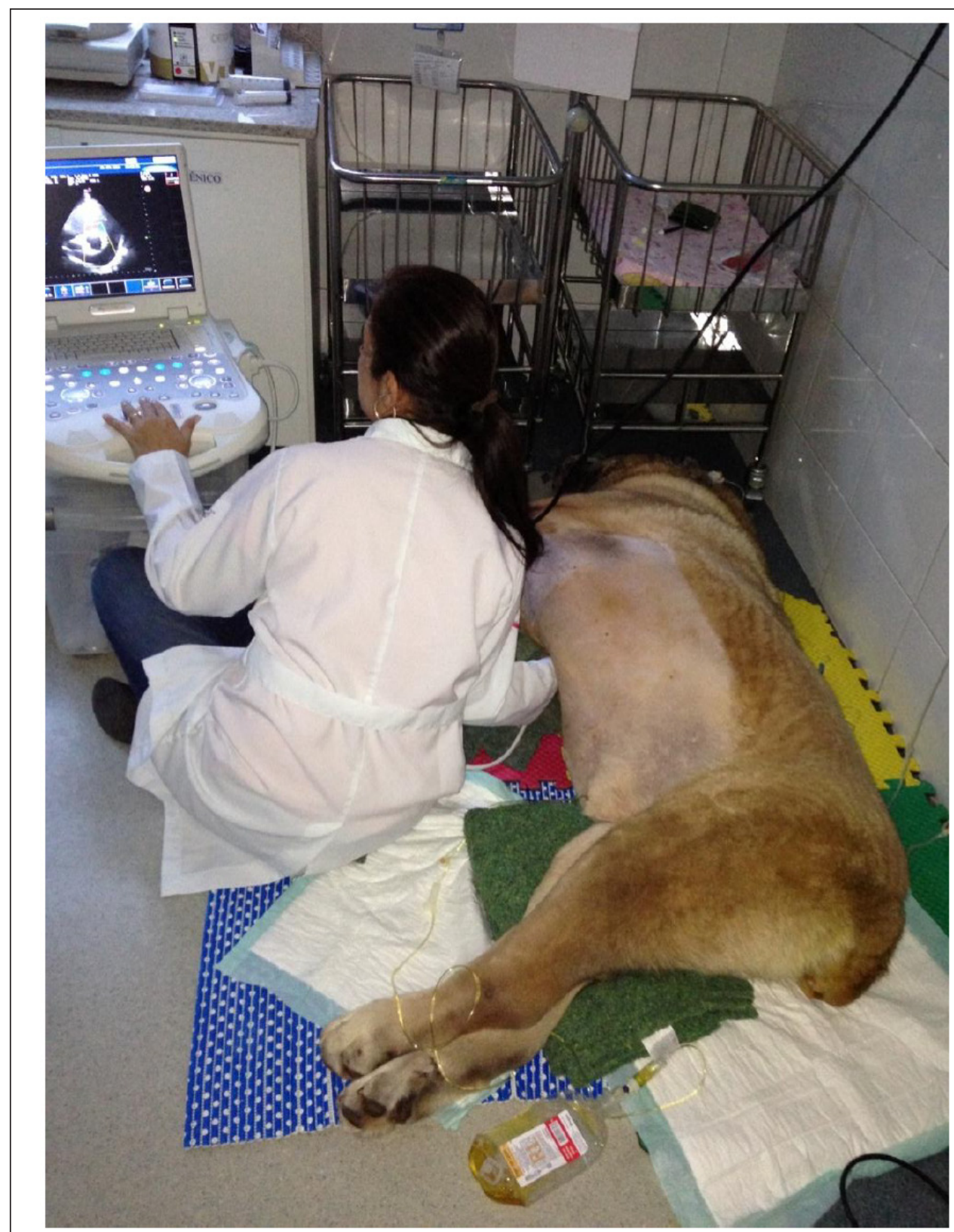

Figure 1 - Echocardiography performed at patient side in the semi-intensive care room in a dog with cardiogenic shock in right lateral recumbency.

chambers images, with the visualization of the atriums and ventricles, interatrial and interventricular septum, aorta and left ventricle outflow tract are performed. Additionally, images in the parasternal long and short axis are acquired (CHACKO \& BRAR, 2014). In veterinary medicine a single study was performed to verify whether training of veterinary emergency physicians would increase the accuracy of FATE in the interpretation of cardiovascular and non- cardiovascular conditions in dogs in the emergency room. In this study veterinarians were trained to acquire images in the right parasternal short axis to visualize the left atrium and ventricle and the aorta, and also the apical four and five chambers images. After training, $90 \%$ of the participants were able to identify pleural effusion, 95\% pericardial effusion and $86 \%$ left atrium enlargement. However, this training was not able to prepare veterinary physicians 
to assess volume status, presence of a cardiac mass, ventricular enlargement or hypertrophy nor other specific heart diseases (TSE et al., 2013).

Through FATE it is possible to evaluate the relative size of the heart chambers (LABOVITZ et al., 2010), particularly the identification of left atrial enlargement (DEFRANCESCO, 2013). In animals, the left atrium is usually compared to the aorta in the right parasternal short axis image at the heart base. In normal patients the left atrium: aorta ratio should be less than 1.3 in cats and 1.5 in dogs. Values greater than 2.0 are highly suggestive of volume overload and congestion, indicating the presence of congestive heart failure (RISHNIW \& ERB, 2000; ABBOTT \& MACLEAN, 2006; BOON, 2011). In one study echocardiographic measurement of left atrium diameter $(>16.5 \mathrm{~mm})$ was shown to help differentiate cases of dyspnea due to congestive heart failure from respiratory disease (SMITH \& DUKES-MCEWAN, 2012).

Systolic function assessment is fundamental in hemodynamically unstable patients because an adequade amount of blood must be pumped from the heart to perfuse the peripheral tissues and meet the metabolic needs of the body (BOON, 2011). Moreover, the presence of hypotension, combined with a decrease in ventricular function, requires optimization of fluid therapy or inotropic assistance (CHACKO \& BRAR, 2014). The purpose of this examination is to facilitate and expedite therapeutic choices; however, FATE will differentiate normal or minimally compromised patients from abnormal or significantly compromised ones (LABOVITZ et al., 2010), since the systolic function is dependent on factors such as preload, afterload, contractility, distensibility, coordinated contraction and heart rate (BOON, 2011).

Systolic dysfunction is characterized by a decreased ability of the heart to pump blood and a consequent decrease in ejection fraction. Left ventricular systolic function can be visually evaluated (subjective evaluation) or by estimating the ejection fraction, which is the percentage of diastolic volume ejected during systole. Quantification of the ejection fraction can be performed in the same way in both people and animals, through the parasternal short axis image, from which the left ventricle internal diameter during systole and diastole can be measured using M mode (BOON, 2011; CHACKO \& BRAR, 2014). However, serial echocardiographic studies are necessary to assess the response of patients to therapeutic interventions, since M mode estimates may be affected by factors influencing preload and afterload. Furthermore, ejection fraction may be over-estimated in patients with vasodilatation due to low systemic vascular resistence (CHACKO \& BRAR, 2014).
Maintenance of right ventricle function allows the right atrium to keep a low pressure that it is appropriate to the venous blood return and also to pulmonary vasculature perfusion. Right ventricular function can be visually assessed in man and animals (BOON, 2011). Furthermore, in people the ratio between the area of the right and left ventricle is used to estimate dilatation of the right ventricle, these measures can be obtained from the apical four chambers image. The interventricular septum should also be evaluated, in cases of overload volume in the right side of the heart the septum is deviated to the left. Under these conditions, the left ventricle loses its circular shape and assumes a " $D$ " form that can be viewed in the parasternal short axis image (CHACKO \& BRAR, 2014). In veterinary medicine right ventricle function is most commonly visually assessed (subjective evaluation). The movement of the tricuspid annulus is assessed by $\mathrm{M}$ mode, and pulmonary artery pressure estimation is by measurement of the velocity of tricuspid valve regurgitation. It is not possible to accurately estimate right ventricle ejection (BOON, 2011).

Blood volume and response to fluid therapy must be monitored precisely in patients in the emergency room. Left ventricle obliteration during systole, visualized in the parasternal short axis view at the papillary muscle level, suggests hypovolemia (CHACKO \& BRAR, 2014). Blood volume can also be estimated in people by measurement of the variation in diameter of the inferior vena cava (IVC) just below the diaphragm during respiratory movements. During inspiration the negative intrathoracic pressure causes a negative intraluminal pressure which reduces the diameter of the IVC and increases venous return to the heart. In patients with hypovolemia the IVC diameters vary more with inspiration and expiration compared to normovolemic patients (LABOVITZ et al., 2010). This parameter is called the IVC collapsibility index and it is calculated from the difference between maximum and minimum IVC diameter, divided by the maximum value with the M mode (VERMEIREN et al., 2015). Futhermore, in human patients an IVC diameter greater than $2 \mathrm{~cm}$ in patients with spontaneous breathing indicates that the pressure on the right side of the heart is increased (CHACKO \& BRAR, 2014). There are some limitations of this index, for example, in patients being mechanically ventilated, the IVC remains dilated and may not collapse (VERMEIREN et al., 2015). This technique is yet to be described in small animals.

Echocardiography is the most sensitive and specific non-invasive method to diagnosis pericardial effusion (PE) in people (FEIGENBAUM, 1994) and 
animals. Very small quantities of fluid (from $15 \mathrm{ml}$ ) can be detected (BERG \& WINGFIELD, 1984). Ultrasonographic examination of $\mathrm{PE}$ is characterized by the presence of an anechoic space between the epicardium and the pericardium and, when the fluid volume is great, the heart may seem to be "dancing" from one side to another within the pericardial space. Pericardial effusion is easily identified by conventional transthoracic echocardiography (CHACKO \& BRAR, 2014). However, it cannot be detected behind the right and left atrium, because in this region the parietal and visceral pleura are bonded more tightly to the heart base (BOON, 2011). Studies have also shown high sensitivity and specificity in the detection of pericardial effusion by focused echocardiography in traumatized patients in the emergency room in people (MAYRON et al., 1988; MANDAVIA et al., 2001; JONES et al., 2003).

Cardiac tamponade is an emergency condition and a possible consequence of pericardial effusion that can be identified by echocardiography by the presence of diastolic collapse of the right atrium and ventricle (CHACKO \& BRAR, 2014). Additionally, the lumen of the left ventricle may be reduced and its walls may appear thickened during diastole as a result of decreased venous return to the left cardiac chambers ("pseudohypertrophy") (BOON, 2011). It is worth emphasizing that the diagnosis of cardiac tamponade is based on clinical signs, such as hypotension, tachycardia, paradoxical pulse and jugular distension. When emergency pericardiocentesis is indicated safety may be improved by performing it under echocardiographic guidance to show the best site for thoracic puncture (LABOVITZ et al., 2010; BOON, 2011).

Pleural effusions can be easily identified during FATE based on the presence of hypoechoic areas between the parietal and visceral pleura, although this is not the focus of this assessment. Thoracic ultrasound is more useful than radiography in cases of pleural effusion because the fluid is an excellent medium for sound transmission. When there is fluid in the pleural space the edges of the heart and the lungs are better visualized; therefore, there is a better acoustic window which allows a better evaluation of cardiac chambers, especially the left atrium. On thoracic radiographs the presence of pleural effusion obscures the cardiac silhouette, pulmonary fields and vasculature. Conversely, ultrasound helps to diagnose, quantify, characterize the fluid and guide thoracocentesis (TIDWELL, 1992; DEFRANCESCO, 2013).

\section{Clinical applications of FATE}

There are several clinical conditions described in the medical literature in which FATE has the potential to alter the therapeutic management of patients (LABOVITZ et al., 2010). In veterinary medicine this type of evaluation is still being developed as a preliminary diagnosis method and initial guide for the management of patients in the emergency room (TSE et al., 2013). Patient side ultrasonography has been described in animals for identification of free fluid in the abdominal cavity (BOYSEN et al., 2004) and the presence of pneumothorax, pleural effusion and pulmonary edema (LISCIANDRO et al., 2008).

\section{Shock/hypotension}

Shock is a clinical syndrome in which there is an inadequate oxygenation of tissues and cells due to circulatory failure (VINCENT \& BACKER, 2013). There are different classifications of shock that vary according to the underlying disease, such as hypovolemic, cardiogenic, obstructive, distributive and shock related to poisoning (JONES \& KLINE, 2014). However, a fundamental characteristic of any type of shock is the presence of hypotension (SINGER et al., 2016). For patients with unkown cause of hypotension, the greatest advantage of FATE is the possibility to differentiate the types of shock. It is extremely important to differentiate cardiogenic shock from other types of shock, so that the appropriate therapy can be implemented as soon as possible (LABOVITZ et al., 2010).

Given the importance of proper and rapid evaluation of patients in shock MOK (2016) has developed a simplified approach of FATE that is specifically directed to the management of different types of shock. The $\mathrm{M}$ mode echocardiographic image of a dog with distributive shock caused by pancreatitis showing the impairment in cardiac contractility can be seen in figure $2 \mathrm{~A}$.

\section{Cardiac arrest}

Since the focused echocardiography is a faster examination compared to $\mathrm{CE}$ it has been extensively used in acute conditions, in the management of critically ill patients and during resuscitation (OZEN et al., 2016). Patients with cardiac arrest require immediate diagnosis and prompt treatment, additionally these patients should be quickly evaluated to identify the cause of the cardiac arrest and whether it can be reversed. The purpose of FATE in patients with cardiac arrest is to improve cardiopulmonary resuscitation by the differentiation of asystole and electrical activity that does not generate pulse, determining the cause of cardiac arrest and to assist the resuscitation procedure at bedside (BREITKREUTZ et al., 2007; LABOVITZ et al., 2010). 


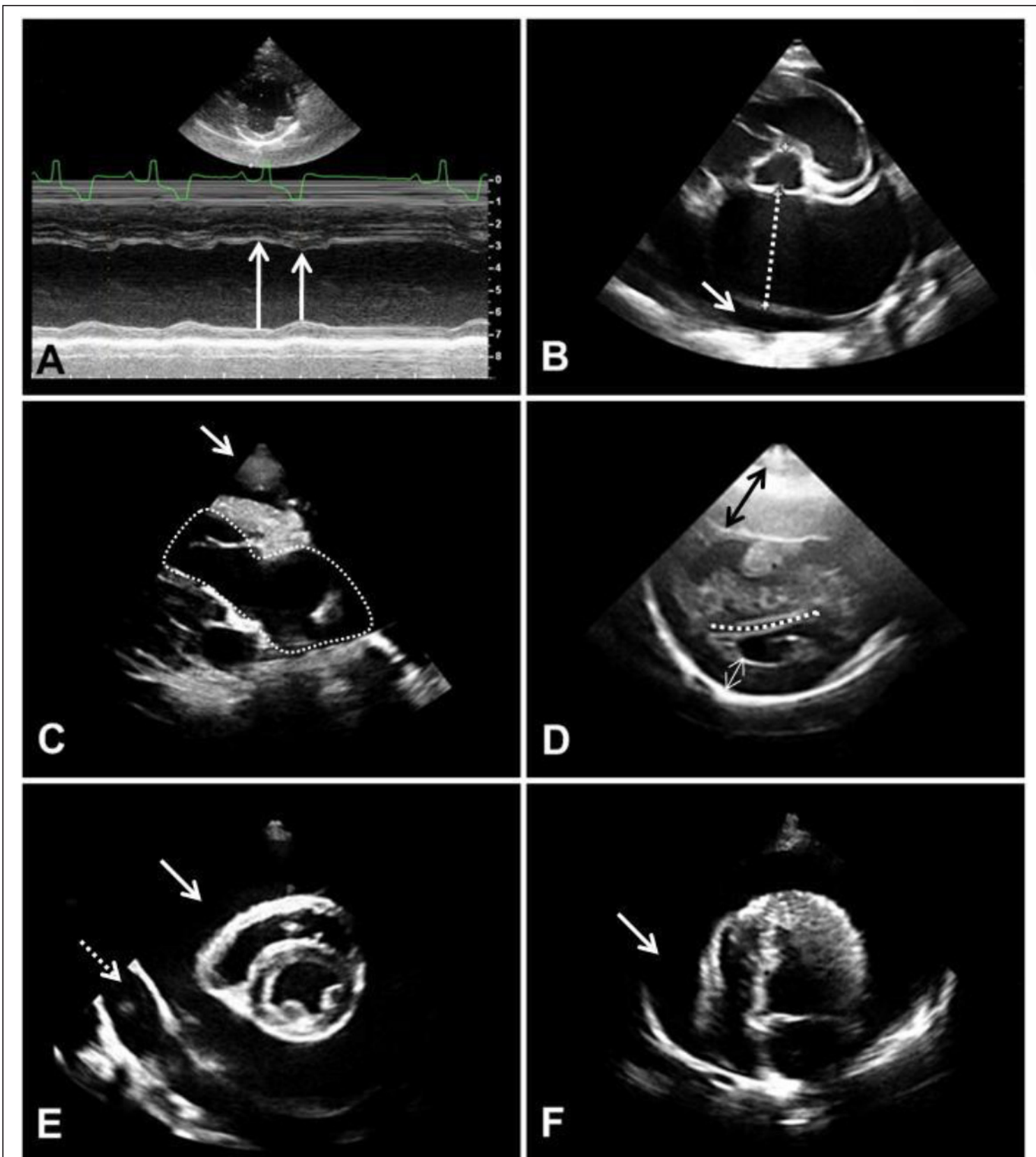

Figure 2 - Echocardiographic images showing (A) the impairment in cardiac contractility evidenced by the arrows, in which the left ventricle cavity does not suffer much change in its diameter comparing systole (short arrow) and diastole (long arrow), in a dog with distributive shock (right parasternal short axis image at the level of chordae tendinea); (B) an enlarged left atrium (dotted line) (left atrium-to-aorta ratio $>2.0$ ) and pericardial effusion (arrow) in a cat with hypertrophic cardiomyopathy (right parasternal short axis image at the heart base); (C) pleural effusion (arrow) and a dilated right atrium and ventricle (dotted line) in a dog with dyspnea and pulmonary hypertension (four chambers right paraesternal long axis image); (D) hypertrophy of the right ventricular wall (black arrow), flattening of the interventricular septum (dotted line) and pseudohypertrophy of the left ventricle (white arrow) in a dog with pulmonary hypertension (right parasternal short axis image at the level of chordae tendinea); (E) pleural (dotted arrow) and pericardial (arrow) effusion in a dog admitted for dyspnea (right parasternal short axis image at the level of chordae tendinea); (F) pericardial effusion (arrow) in a syncopal dog (apical four chambers left paraesternal image).

A number of factors influence success of resuscitation, such as cardiac rhythm, access to defibrillation, rapid chest compression, patient age, presence of comorbidities and cardiopulmonary 
resuscitation time (SASSON et al., 2010; REA et al., 2010). Several medical studies have discussed the application of FATE to decide when to cease cardiopulmonary resuscitation. Research has shown that the absence of movement of the ventricular wall during resuscitation implies a lower survival rate. This information can be used to decide when to end the resuscitation procedure (AICHINGER et al., 2012).

\section{Respiratory distress}

Evaluation of the size of the left atrium in animals with dyspnea (Figure 2B) can be useful, especially in cats, when physical examination and thoracic radiography fail to provide a definitive diagnosis. Cats with heart failure have nonspecific changes on auscultation, and the heart rate may be normal, increased or decreased (GOUTAL et al., 2010). Moreover, the prevalence of heart murmur in cats with cardiomyopathy $(\mathrm{CM})$ is $55.7 \%$ (FERASIN et al., 2003), indicating that many affected cats do not have an audible murmur. SMITH \& DUKESMCEWAN (2012) reported that the absence of heart murmur was common in cats with heart failure, while arrhythmias and gallop rhythms were prevalent. These findings differ from what is observed in dogs, where there is an excellent correlation between the presence of the heart murmur and chronic degenerative valvular disease, and also the intensity of the murmur to the severity of the disease (HAGGSTROM et al., 1995).

Another peculiarity of cats is that cardiogenic pulmonary edema can manifest itself in a variety of ways and at different locations on the thoracic radiograph (RUSH et al., 2002). Radiographic findings of cardiogenic pulmonary edema in cats are more variable than in dogs because it has different distribution in the lung field (LAMB, 2007). In a study evaluating the radiographic pattern in cats with cardiogenic pulmonary edema, $17 \%$ had diffuse and uniform distribution, $61 \%$ had diffuse and non-uniform distribution, in $17 \%$ it was multifocal and in $4 \%$ focal (BENIGNI et al., 2009). Detection of pericardial effusion in cats with cardiomegaly and dyspnea is highly suggestive of heart failure (HALL et al., 2007).

Patients presenting with dyspnea, cyanosis and syncope without obvious changes in cardiac auscultation should also be investigated for pulmonary hypertension ( $\mathrm{PH})$. Primary etiologies of PH include left congestive heart failure, (postcapillary $\mathrm{PH}$ ), thromboembolism, chronic respiratory disease, heartworm or right to left shunting (precapillary PH) (JOHNSON, 2016).

Acute pulmonary embolism (PE) can lead to a dramatic clinical deterioration and it is difficult to diagnose because the clinical signs are nonspecific. The gold standard for the diagnosis of PE is contrast computed tomography but in severely impaired patients CT may be inappropriate. Echocardiographic examination has been regarded as an excellent bedside diagnostic method in people with PE (GOLDHABER, 2002).

In patients with $\mathrm{PH}$ the echocardiographic examination may show dilatation of the pulmonary artery, hypertrophy and enlargement of the right ventricle, rectified interventricular septum with paradoxical movement, systolic dysfunction of the right ventricle, right atrium dilatation and decreased right ventricle lumen (Figure 2C e 2D). All these changes can be seen by FATE; however, the Doppler modality is the most used to identify PH. Using Doppler it is possible to estimate the pulmonary artery pressure gradient by measuring the velocity of tricuspid valve regurgitation, thereby $\mathrm{PH}$ can be graded as mild, moderate or severe. $\mathrm{PH}$ is diagnosed once the maximum velocity of tricuspid valve regurgitation is greater than $2.8 \mathrm{~m} / \mathrm{s}^{-1}$ (BOON, 2011).

Pleural effusion is another potential diagnosis in patients with dyspnea and muffled heart and lung sounds on cardiopulmonary auscultation and can also be easily identified during FE (Figure 2E) (DEFRANCESCO, 2013).

\section{Thoracic trauma}

DEFRANCESCO (2013) stated that all dogs and cats that have suffered thoracic trauma should be evaluated by ultrasound before radiographic examination. Patient side thoracic ultrasound is indicated to identify fluid around the heart or in the thoracic cavity which may indicate post traumatic bleeding. FATE aims to evaluate the presence of pericardial effusion and potential myocardium injury that require immediate surgical intervention (LABOVITZ et al., 2010).

In human patients with bluntand penetrating thoracic traumas focused echocardiography has been used for over 20 years (LABOVITZ et al., 2010). The use of FATE has reduced the time to diagnosis, thereby allowing rapid institution of emergency thoracotomy and laparotomy when required, thus decreasing morbity and mortality of thoracic trauma (SYMBAS et al., 1999; ROZYCKI et al., 1999).

Beyond cases of thoracic trauma (hemorrhage), echocardiographic examinations are also indicated for the diagnosis of right congestive heart failure with chronic pericardial effusion (Figure 2F) and syncope or hypotension with acute pericardial effusion (BOON, 2011). 


\section{CONCLUSION}

The use of ultrasound modalities in the emergency room as a diagnostic aid and for monitoring of critically ill patients is already widespread in the intensive care units of human hospitals. However, there are few references on this subject in the intensive care of small animals. In this context FATE, when used at the patient side, has many advantages compared to other diagnostic modalities - even when carried out by a noncardiologist doctor or veterinarian. Despite the fact that this method seems to be promising, more studies are need to define the necessary adaptations and standardizations of FATE for use in animals in the emergency room.

\section{ACKNOWLEDGEMENTS}

The authors acknowledge the financial support of Coordenação de Aperfeiçoamento de Pessoal de Nível Superior (CAPES).

\section{REFERENCES}

ABBOTT, J.A.; MACLEAN, H.N. Two-dimensional echocardiographic assessment of the feline left atrium. Journal of Veterinay Internal Medicine, v.20, p.111-119, 2006. Available from: <http://onlinelibrary. wiley.com/doi/10.1111/j.1939-1676.2006.tb02830.x/epdf>. Accessed: Sept. 10, 2016. doi: 10.1111/j.1939-1676.2006.tb02830.x.

AICHINGER, G. et al. Cardiac movement identified on prehospital echocardiography predicts outcome in cardiac arrest patients. Prehospital Emergency Care, v.16, p.251-255, 2012. Available from: $<$ http://dx.doi.org/10.3109/10903127.2011.640414>. Accessed: Sept. 10, 2016. doi: 10.3109/10903127.2011.640414.

BEAULIEU, Y. Bedside echocardiography in the assessment of the critically ill. Critical Care Medicine, v.35, supl.5, p.235-249, 2007. Available from: <http://www.scielo.br/scielo.php?script=sci_artte xt\&pid=S1679-45082015000400644> $>$. Accessed: Sept. 10, 2016. doi: 10.1590/S1679-45082015MD3271.

BENIGNI, L. et al. Radiographic appearance of cardiogenic pulmonary oedema in 23 cats. Journal of Small Animal Practice, v.50, p.9-14, 2009. Available from: <http://onlinelibrary.wiley. com/doi/10.1111/j.1748-5827.2008.00655.x/pdf>. Accessed: Sept. 14, 2016. doi: 10.1111/j.1748-5827.2008.00655.x.

BERG, R. J.; WINGFIELD, W. Pericardial Effusion in the Dog: A review of 42 cases. Jounal of the American Animal Hospital Association, v.20, n.5, p.721-730, 1984.

BOON, J.A. Veterinary echocardiography. 2ed. Ames: WileyBlackwell, 2011. 767p.

BOYSEN, S.R. et al. Evaluation of a focused assessment with sonography for trauma protocol to detect free abdominal fluid in dogs involved in motor vehicle accidents. Journal of American Veterinary Medical Association, v.225, n.8, p.1198-1204, 2004. Available from: $<$ https://www.researchgate.net/publication/8199944 Evaluation_of_a_Focused_Assessment_With_Sonography_for Trauma_Protocol_to_Detect_Free_Abdominal_Fluid_in_Dogs
Involved_in_Motor_Vehicle_Accidents $>$. Accessed: Sept. 10, 2016. doi: $10.2 \overline{4} 60 /$ javma.2004.225.1198.

BREITKREUTZ, R. et al. Focused echocardiographic evaluation in resuscitation management: concept of an advanced life supportconformed algorithm. Critical Care Medicine, v.15, supl.5, p.150161, 2007. Available from: <www.emergencyultrasoundteaching. com/assets/.../Code_2007_Breitkreutz_CCM.pdf>. Accessed: Sept. 10, 2016. doi: 10.1097/01.CCM.0000260626.23848.FC.

CASAROTO, E. et al. Bedside echocardiography in critically ill patients. Medical Developments, v.13, n.4, p.644-646, 2015. Available from: $<$ http://www.scielo.br/scielo.php?script=sci artte xt\&pid=S1679-45082015000400644>. Accessed: Sept. 14, 2016. doi: 10.1590 S1679-45082015MD3271.

CHACKO, J.; BRAR, G. Bedside ultrasonography: applications in critical care: part I. Indian Journal of Critical Care Medicine, v.18, n.5, p.301-309, 2014. Available from: <http:/www.ijccm.org/ article.asp? issn $=0972-5229$; year $=2014$; volume $=18$; issue $=5$; spage $=301$; epage $=309$; aulast $=$ Chacko $>$. Accessed: Sept. 14, 2016. doi: 10.4103/0972-5229.132492.

CHETBOUL, V. Advanced techniques in echocardiography in small animals. Veterinary Clinics of North America: Small Animal Practice, v.40, p.529-543, 2010. Available from: <http://dx.doi. org/10.1016/j.cvsm.2010.03.007>. Accessed: Sept. 10, 2016. doi: 10.1016/j.cvsm.2010.03.007

CÔTÉ, E. Echocardiography: common pitfalls and practical solutions. Clinical Techniques in Small Animal Practice, v.20, p.156-163, 2005. Available from: <http://www.sciencedirect.com/ science/article/pii/S1096286705000344>. Accessed: Sept. 10, 2016. doi: $10.1053 /$ j.ctsap.2005.05.003.

DEFRANCESCO, T.C. Management of Cardiac Emergencies in Small Animals. Veterinary Clinics of North America: Small Animal Practice. v.43, p.817-842, 2013. Available from: <http:// dx.doi.org/10.1016/j.cvsm.2013.03.012>. Accessed: Sept. 10, 2016. doi: 10.1016/j.cvsm.2013.03.012.

FEIGENBAUM, H. Echocardiography. 5ed. Philadelphia: Lea \& Febinger, 1994. 659p.

FERASIN, L. et al. Feline idiopathic cardiomyopathy: a retrospective study of 106 cats (1994-2001). Journal of Feline Medicine and Surgery. v.5, n.3, p.151-159, 2003. Available from: $<$ http://dx.doi.org/10.1016/S1098-612X(02)00133-X>. Accessed: Sept. 14, 2016. doi: 10.1016/S1098-612X(02)00133-X.

GOLDHABER, S.Z. Echocardiography in the management of pulmonary embolism. Annals of Internal Medicine, v.136, n.9, p.691700, 2002. Available from: <http://annals.org/aim/article/715263/ echocardiography-management-pulmonary-embolism $>$. Accessed: Sept. 10, 2016. doi: 10.7326/0003-4819-136-9-200205070-00012.

GOUTAL, C.M. et al. Evaluation of acute congestive heart failure in dogs and cats: 145 cases (2007-2008). Journal of Veterinary Emergency and Critical, v.20, n.3, p.330-337, 2010. Available from: $<$ http://onlinelibrary.wiley.com/doi/10.1111/j.1476-4431.2010.00524.x/ full>.Accessed: Sept. 10, 2016. doi: 10.1111/j.1476-4431.2010.00524.x.

HAGGSTROM, J. et al. Heart sounds and murmurs: changes related to severity of chronic valvular disease in the Cavalier King Charles spaniel. Journal of Veterinary Internal Medicine, v.9, n.2, p.75-85, 1995. Available from: <http://onlinelibrary.wiley.com/ 
doi/10.1111/j.1939-1676.1995.tb03276.x/pdf>. Accessed: Sept. 10, 2016. doi: 10.1111/j.1939-1676.1995.tb03276.x.

HALL, D.J. et al. Pericardial effusion in cats: a retrospective study of clinical findings and outcome in 146 cats. Journal of Veterinary Internal Medicine, v.21, p.1002-1007, 2007. Available from: $<$ http://onlinelibrary.wiley.com/doi/10.1111/j.1939-1676.2007. tb03056.x/epdf >. Accessed: Sept. 10, 2016. doi: 10.1111/j.19391676.2007.tb03056.x.

JOHNSON, L.R. Cor pulmonale and pulmonary thromboembolysm. In:SMITH JR. et al. Manual of canine and feline cardiology. 5 ed. St. Louis: Elsevier, 2016. Cap.10, p.181-197.

JONES A.E. et al. Focused training of e mergency medicine residents in goal-directed echocardiography: a prospective study. Academic Emergency Medicine, v.10, p.1054-1058, 2003 Available from: <http://onlinelibrary.wiley.com/doi/10.1197/S10696563(03)00346-4/pdf>. Accessed: Sept. 10, 2016. doi: 10.1197/ S1069-6563(03)00346-4/pdf.

JONES, A.E.; KLINE, J.E. Shock. In: MARX, J. A. et al. Rosen's emergency medicine: concepts and clinical practice. 8ed. Philadelphia: Saunders, 2014. Cap. 6.

LABOVITZ, A.J. et al. Focused Cardiac Ultrasound in the Emergent Setting: A Consensus Statement of the American Society of Echocardiography and American College of Emergency Physicians. Journal of the American Society of Echocardiography, v.23, p.1225-1230, 2010. Available from: <http://dx.doi.org/10.1016/j echo.2010.10.005>. Accessed: Sept. 10, 2016. doi: 10.1016/j. echo.2010.10.005.

LAMB, C.R. The canine and feline lung. In: THRALL, D.E. Textbook of Veterinary Diagnostic Radiology. 5ed. Philadelphia: Saunders, 2007. Cap.34, p.591-608.

LISCIANDRO, G.R. et al. Evaluation of a thoracic focused assessment with sonography for trauma (TFAST) protocol to detect pneumothorax and concurrent thoracic injury in 145 traumatized dogs. Journal of Veterinary Emergency and Critical Care, v.18, p.258-269, 2008. Available from: <http://onlinelibrary.wiley.com/ doi/10.1111/j.1476-4431.2008.00312.x/epdf>. Accessed: Sept. 14, 2016. doi: 10.1111/j.1476-4431.2008.00312.x.

MANDAVIA, D.P. et al. Bedside echocardiography by emergency physicians. Annals of Emergency Medicine, v.38, p.377-382, 2001. Available from: <http://www.annemergmed.com/article/ S0196-0644(01)17352-X/fulltext>. Accessed: Sept. 10, 2016. doi: $10.1067 / \mathrm{mem} .2001 .118224$

MAYRON R. et al. Echocardiography performed by emergency physicians: impact on diagnosis and therapy. Annals of Emergency Medicine, v.17, p.150-154, 1988. Available from: <http:// www.annemergmed.com/article/S0196-0644(88)80301-9/pdf>. Accessed: Sept. 10, 2016. doi: 10.1016/S0196-0644(88)80301-9.

MELAMED, R. et al. Assessment of the left ventricular function by intensivists using hand-held echocardiography. Chest, v.135, n.6, p.1416-1420, 2009. Available from: <http://www.sciencedirect. com/science/article/pii/S001236920960341X>. Accessed: Sept. 10, 2016. doi: 10.1378/chest.08-2440.

MEYER, S. et al. Review article: non-invasive assessment of cardiac output with portable continuous-wave doppler ultrasound. Emergency Medicine Australasia, v.20, n.3, p.201-208, 2008. Available from:
$<$ http://dx.doi.org/10.1053/j.jvca.2012.03.022>. Accessed: Sept. 10, 2016. doi: 10.1053/j.jvca.2012.03.022.

MOK, K. L. Make it SIMPLE: enhanced shock management by focused cardiac ultrasound. Journal of Intensive Care, v.4, n.51, p.1-17, 2016. Available from: < https://jintensivecare. biomedcentral.com/articles/10.1186/s40560-016-0176-x >. Accessed: Sept. 14, 2016. doi: 10.1186/s40560-016-0176-x.

MOORE C.L.; COPEL J.A. Point of care ultrasonography. New England Journal of Medicine, v.364, n.8, p.749-757, 2011. Available from: <http:/www.nejm.org/doi/full/10.1056/ NEJMra0909487>. Accessed: Sept. 10, 2016. doi: 10.1056/ NEJMra0909487.

OYAMA, M.A. Advances in echocardiography. Veterinary Clinics: Small Animal Practice, v.34, n.5, p.1083-1104, 2004. Available from: <http://dx.doi.org/10.1016/j.cvsm.2004.05.004>. Accessed: Sept. 10, 2016. doi: 10.1016/j.cvsm.2004.05.004.

OZEN, C. et al. Assessment of ventricular wall motion with echocardiography during cardiac arrest to predict survival. Turkish Journal of Emergency Medicine, v.16, n.1, p.12-16, 2016. Available from: <https://www.ncbi.nlm.nih.gov/pmc/articles/PMC4882209/>. Accessed: Sept. 10, 2016. doi: 10.1016/j.tjem.2015.08.001.

REA, T.D. et al. Predicting survival after out-of-hospital cardiac arrest: role of the Utstein data elements. Annals of Emergency Medicine, v.55, p.249-257, 2010. Available from: <http://www. annemergmed.com/article/S0196-0644(09)01556-X/fulltext $>$. Accessed: Sept. 10, 2016. doi: 10.1016/j.annemergmed.2009.09.018.

RISHNIW, M.; ERB, H.N. Evaluation of four 2-dimensional echocardiographic methods of assessing left atrial size in dogs. Journal of Veterinary Internal Medicine, v.14, n.4, p.429435, 2000. Available from: <http://onlinelibrary.wiley.com/ doi/10.1111/j.1939-1676.2000.tb02252.x/pdf>. Accessed: Sept. 10, 2016. doi: 10.1111/j.1939-1676.2000.tb02252.x.

ROZYCKI, G.S. et al. The role of ultrasound in patients with possible penetrating cardiac wounds: a prospective multi-center study. Journal of Trauma and Acute Care Surgery, v.46, p.543-551, 1999.

RUSH, J.E. et al. Population and survival characteristics of cats with hypertrophic cardiomyopathy: 260 cases (1990-1999). Journal of the American Veterinary Medical Association, v.220, p.202-207, 2002. Available from: <http://dx.doi.org/10.2460/javma.2002.220.202>. Accessed: Sept. 14, 2016. doi: 10.2460/javma.2002.220.202.

SASSON, C. et al. Predictors of survival from out-of-hospital cardiac arrest: a systematic review and meta-analysis. Circulation: Cardiovascular Quality and Outcomes, v.3, p.63-81, 2010. Available from: $<$ http://dx.doi. org/10.1161/CIRCOUTCOMES.109.889576>. Accessed: Sept. 10, 2016. doi: 10.1161/CIRCOUTCOMES.109.889576.

SINGER, M. et al. The third international consensus definition for sepsis and septic shock (sepsis-3). Journal of The American Medical Association, v.315, n.8, p.801-810, 2016. Available from: $<$ https://www.ncbi.nlm.nih.gov/pmc/articles/PMC4968574/>. Accessed: Sept. 10, 2016. doi: 10.1001/jama.2016.0287.

SMITH, S.; DUKES-MCEWAN, J. Clinical signs and left atrial size in cats with cardiovascular disease in general practice. Journal of Small Animal Practice, v.53, n.1, p.27-33, 2012. Available from: <http:// onlinelibrary.wiley.com/doi/10.1111/j.1748-5827.2011.01143.x/pdf>. Accessed: Sept. 10, 2016. doi: 10.1111/j.1748-5827.2011.01143.x. 
SPENCER, K.T. et al. Focused Cardiac Ultrasound: Recommendations from the American Society of Echocardiography. Journal of the American Society of Echocardiography. v.26, p.567-581, 2013. Available from: $<\mathrm{http}$ ://www.onlinejase.com/article/S0894-7317(13)00259-9/fulltext>. Accessed: Sept. 10, 2016. doi: 10.1016/j.echo.2013.04.001.

SYMBAS, NP. et al. Blunt cardiac rupture: the utility of emergency department ultrasound. Annals of Thoracic Surgery, v.67, n.5, p.1274-1276, 1999. Available from: <http://dx.doi.org/10.1016/S0003-4975(99)00169-1> Accessed: Sept. 10, 2016. doi: 10.1016/S0003-4975(99)00169-1.

TIDWELL, A.S. Diagnostic Pulmonary Imaging. Problems in Veterinary Medicine, v. 4, n.2, p.239-264, 1992.

TSE, Y.C. et al. Evaluation of a training course in focused echocardiography for noncardiology house officers. Journal of Veterinary Emergency and Critical Care, v.23, n.3, p.268-273,
2013. Available from: <http://onlinelibrary.wiley.com/doi/10.1111/ vec.12056/pdf>. Accessed: Sept. 10, 2016. doi: 10.1111/vec.12056.

VERMEIREN, G.L.J. et al. Cardiac ultrasonography in the critical care setting: a practical approach to asses cardiac function and preload for the "non-cardiologist". Anaesthesiology Intensive Therapy, v.47, p.89-104, 2015. Available from: <https://com-anest. sites.medinfo.ufl.edu/files/2015/06/2016-Cardiac-Ultrasound.pdf.>. Accessed: Sept. 10, 2016. doi: 10.5603/AIT.a2015.0074.

VINCENT, J.L.; BACKER, B. Circulatory shock. New England Journal of Medicine, v.369, p.1726-1734, 2013. Available from: $<$ http://www.nejm.org/doi/full/10.1056/nejmra1208943\#t=article > Accessed: Sept. 10, 2016. doi: 10.1056/nejmra1208943.

WARE, W.A. Cardiovascular Disease in Small Animal Medicine. 1ed. London: Manson Publishing, 2011. 396p. 